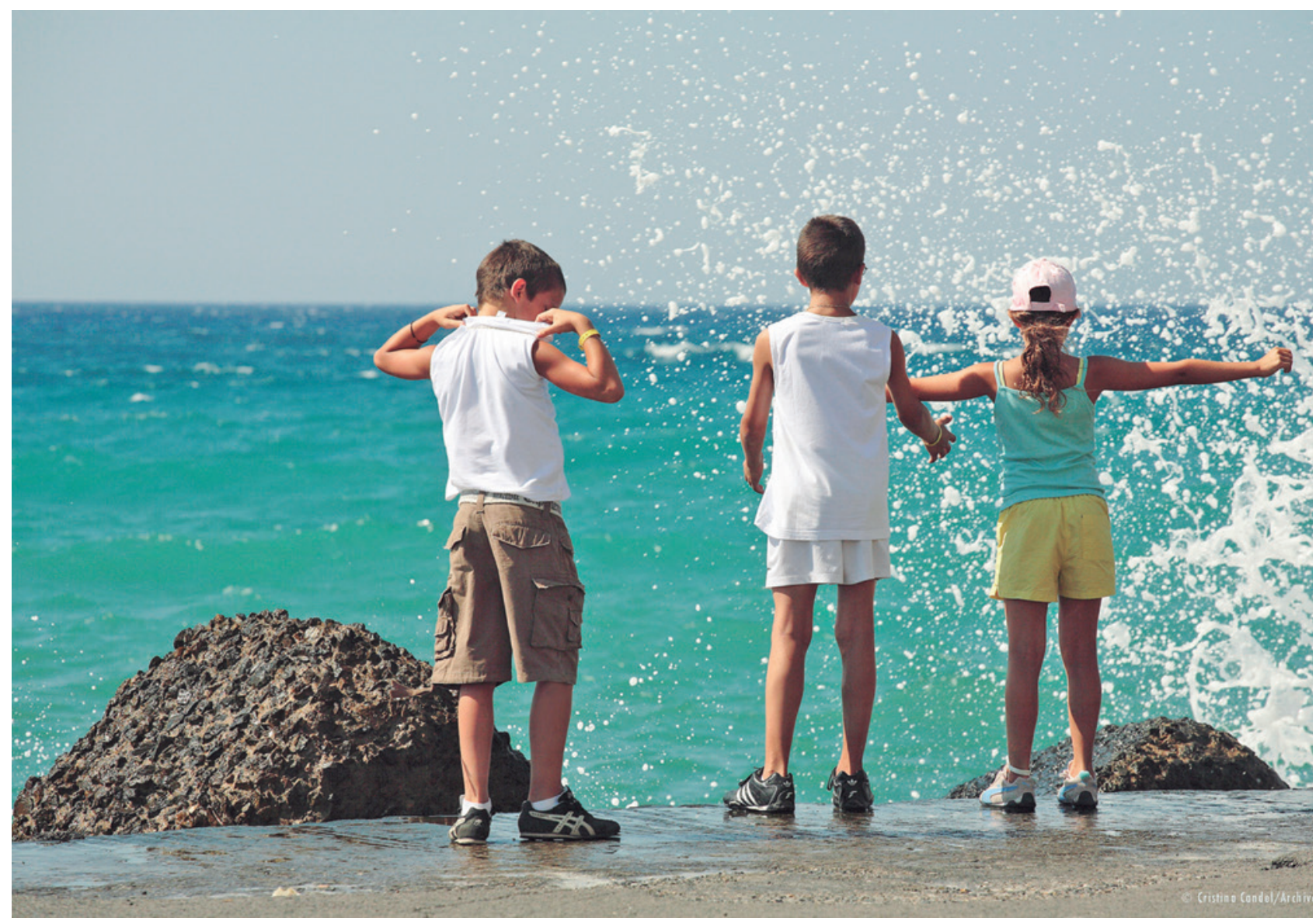

\title{
La música en el aula activa
}

La música se considera una de las disciplinas que puede desarrollar las inteligencias múltiples en equilibrio con mayor facilidad, siempre que el proceso de enseñanzaaprendizaje se lleve a cabo de manera lúdica a través de pedagogías activas. A pesar de ello, esta materia se encuentra poco presente en la educación obligatoria debido al horario escolar

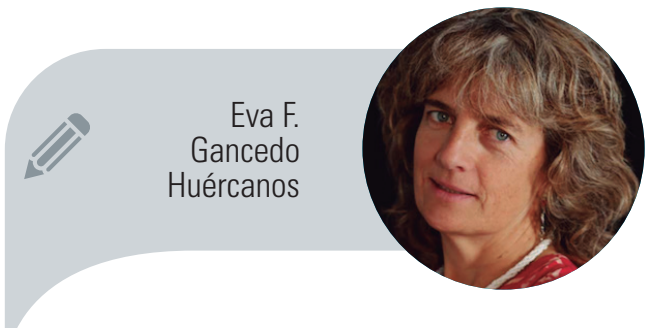

Universidad Autónoma de Madrid Universidad de Valladolid (Campus Segovia) eva@evagancedo.com

@GancedoEva estipulado por la ley de educación española. En cuanto al proceso de enseñanzaaprendizaje de la música en las aulas de las escuelas de música y conservatorios, está evolucionando hacia las pedagogías activas, pero aún de manera lenta y desigual. 
Los contextos educativos contemporáneos requieren una reforma pedagógica para acomodarse a las nuevas demandas y necesidades de la sociedad. Para ello, se propone al profesorado acercar al alumnado a la experiencia musical teniendo como principal objetivo la adquisición de competencias y el desarrollo de sus inteligencias múltiples en equilibrio.

Sugerimos en el artículo el uso de diversas estrategias educativas aplicadas al aula para favorecer el proceso de enseñanza-aprendizaje, con un enfoque innovador, que se sumarán a las ya conocidas maneras de aprender la música. El conocimiento y uso de estas estrategias educativas lleva al profesorado a la transformación y a la creación de actividades pedagógicas personalizadas a cada individuo y para cada grupo. Esta manera de trabajar en el aula deriva en una evaluación formativa del alumnado y del profesorado y, además, enriquece el currículo de educación.

\section{Pedagogías innovadoras para la música}

El desarrollo de las inteligencias múltiples va emparejado, desde hace tiempo, a cierto tipo de actividades musicales en el aula, de percepción y expresión, como pueden ser:

7 Corporal-kinestésica: la representación coreográfica de una danza o de una sucesión de movimientos sobre diferentes tipos de música; la interpretación de un instrumento con su manera particular de tocarlo.

$\boldsymbol{\lambda}$ Interpersonal: la interpretación vocal e instrumental en grupo; la danza por parejas o grupal; las estrategias de aprendizaje cooperativo.

7 Espacial: la interpretación de partituras no convencionales o convencionales, la audición activa, los dictados musicales, la realización de un conjunto de movimientos en el aula de música.

$\boldsymbol{\lambda}$ Lingüística: la interpretación de prosodias rítmicas; el trabajo con onomatopeyas; el canto de canciones con sus letras; la musicalización de un tex-

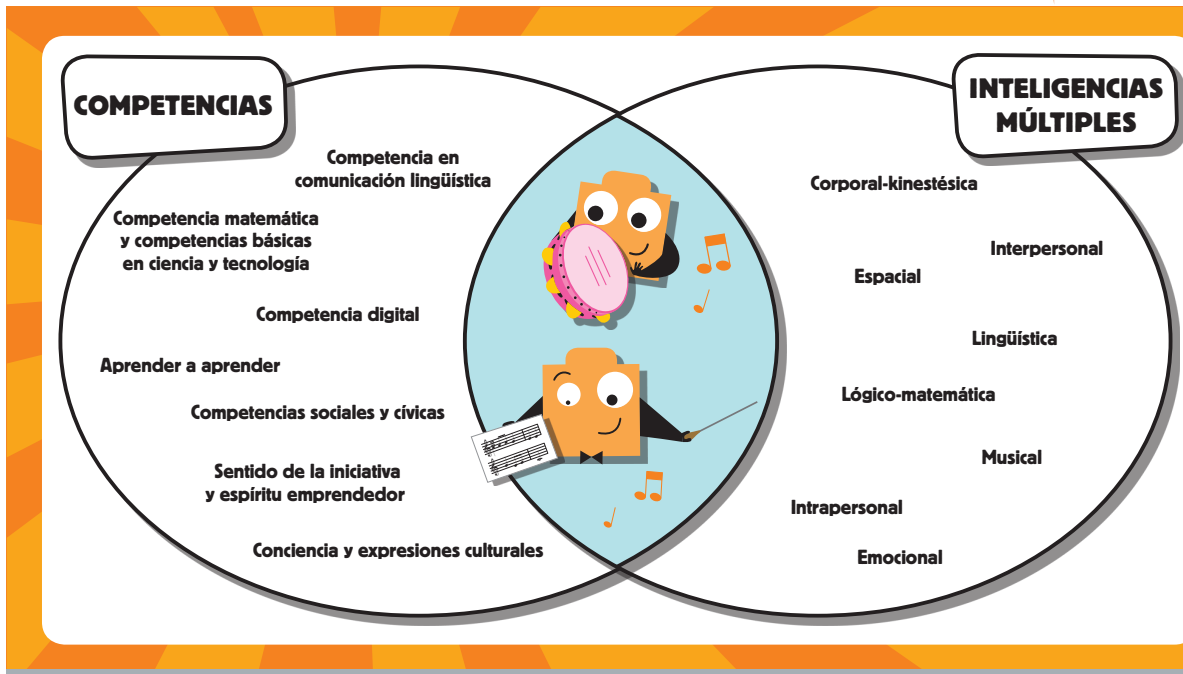

to; la creación de un libreto para una obra musical.

入 Lógico-matemática: la interpretación rítmica de agrupaciones de figuras o notas musicales de diferente valor y altura en diferentes tipos de compás; la realización de una serie de pasos de una danza en un determinado compás; la lectura de obras rítmicas y melódicas.

$\lambda$ Musical: el canto; la interpretación de los instrumentos del aula; la realización de dictados musicales rítmicos, melódicos y armónicos; la audición activa; la pronunciación y la entonación de letras de canciones en varios idiomas.

$\boldsymbol{\lambda}$ Intrapersonal: el aprendizaje sobre uno mismo o una misma a partir del comportamiento de los iguales y del profesorado en el desarrollo de una actividad musical.

7 Emocional: práctica de una comunicación asertiva en las actividades grupales de expresión corporal, vocal e instrumental; reconocimiento de las emociones ajenas y reconocimiento y control de las emociones propias en este tipo de actividades; desarrollo de la automotivación con cualquier experiencia musical.

Muchas de estas actividades derivan de corrientes pedagógicas musicales activas que llevan aplicándose en el aula desde hace aproximadamente un siglo (Dalcroze, Willems, Orff, Kodaly...).

La novedad pedagógica para el aula de música consiste en añadir, a este tipo de corrientes educativas musicales, unas estrategias pedagógicas generales aptas para cualquier disciplina, como son las 


\section{IIII) ÂQORA DE PROFESORES}

У Crear una rúbrica para todas las actividades del aula cuyas categorías a evaluar sean las acciones relacionadas con el emprendimiento.

$\forall \quad$ Crear murales en los que se muestren las emociones que se generan en el alumnado cuando hay un proceso de enseñanza-aprendizaje equilibrado y qué les emociona positivamente en el aula de música.

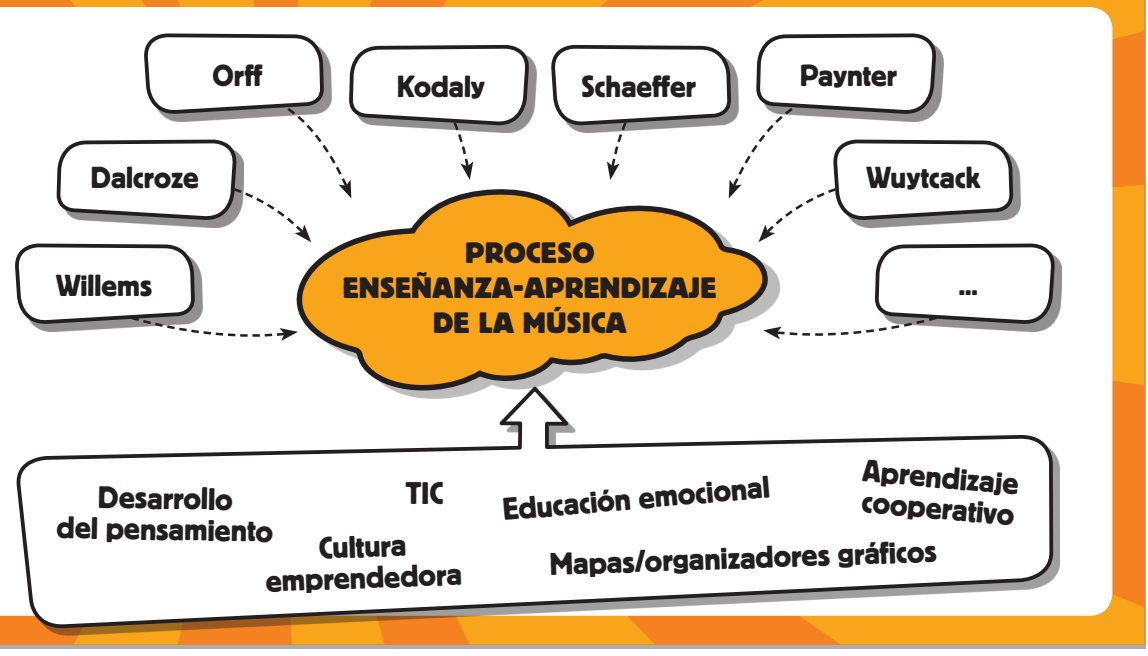

relacionadas con el desarrollo del pensamiento, el aprendizaje cooperativo, la cultura emprendedora, la educación emocional y el uso de las nuevas tecnologías. Su aplicación proporciona, como resultado, una gran autonomía del alumnado en la adquisición de conocimientos. Más adelante se plantean algunos ejemplos de su utilización en el aula de música.

La enseñanza de la música a través de pedagogías activas contribuye a desarrollar capacidades en el alumnado que le permiten alcanzar, de manera sencilla, los objetivos correspondientes de las etapas de infantil, primaria y secundaria y adquirir los contenidos musicales de los tres bloques que plantea la ley de educación como son el aprendizaje de la escucha activa, las habilidades para la interpretación musical y las capacidades expresivas y creativas desde el conocimiento y práctica de la danza.

\section{Estrategias para el desarrollo del pensamiento}

Coincidimos con autores como Vicente, Howard-Jones o Morgado en la preponderancia de tres elementos básicos a la hora de abordar el proceso de enseñanzaaprendizaje: los procesos cognitivos, las estrategias de pensamiento que se utilizan y las interacciones.

En cuanto a los procesos cognitivos, Rafael Mesa y Jacobo Calvo en el proyecto "Pieza a Pieza" (2018) afirman que "en los currículos actuales se potencia el uso de una variedad de procesos cognitivos, tales como: identificar, analizar, reconocer, asociar, reflexionar, razonar, deducir, inducir, decidir, explicar, crear, etc.". También exponen cómo el alumnado genera su propio conocimiento a través de esta manera de aprender: "Se estimula la reflexión y el pensamiento crítico en el alumnado, así como los procesos de construcción individual y colectiva del conocimiento, y se favorece el descubrimiento, la investigación, el espíritu emprendedor y la iniciativa personal".

Diferentes autores a lo largo de la historia han trabajado sobre el desarrollo del pensamiento, tales como Decroly, Escamilla, Gardner, Goleman o Perkins, y nos han dejado una serie de estrategias pedagógicas que han sido llamadas de diferentes maneras, como rutinas o técnicas de pensamiento. A través de organizadores, estas técnicas permiten al alumnado visualizar su propio proceso de pensamiento y aprendizaje en cuanto a la adquisición de contenidos.

Todas estas técnicas para el desarrollo del pensamiento son aplicables a la asignatura de música y complementan la tradicional pedagogía que se basa en la interiorización de contenidos a través de la percepción y expresión musicales. Para poder utilizarlas de una manera productiva, es importante que el profesorado tenga presentes todos los contenidos conceptuales musicales que se han de enseñar en cada nivel educativo. Así, a través de estas técnicas, el alumnado asentará conceptos o pares de conceptos opuestos que haya adquirido con anterioridad a través de la práctica musical, como pueden ser: silencio/sonido, forma o estructura, características del sonido, elementos de la música, pulso, compás, tempo...

Dependiendo del contenido conceptual, actitudinal o metodológico y del nivel 
de conocimiento musical, se escogerá una u otra técnica. Veamos ejemplos de actividades asociadas al proceso enseñanzaaprendizaje de la música relacionadas con algunas de las rutinas de pensamiento:

7 Veo, pienso, me pregunto, comparto. Se sugiere al alumnado que observe una representación pictórica en la que aparecen una serie de instrumentistas barrocos interpretando música con un instrumento. En una tabla de tres columnas escriben lo que ven, lo que piensan al respecto y lo que se preguntan. Posteriormente comparten sus ideas.

$\rightarrow$ Un paso al interior. Se propone al alumnado que adquieran el papel de un determinado concepto musical, época o personaje que se esté trabajando en la clase, como puede ser el compás, pasando a ser ellos mismos dichos conceptos. Después escriben y comparten, ¿qué perciben siendo el compás? ¿Qué saben? ¿Qué les preocupa?

त Titular, bla-bla-bla. Tras la lectura de un texto sobre una directora de orquesta, las alumnas y los alumnos escriben un titular de prensa que indique lo más importante a conocer de dicha persona. El intercambio de titu-

\section{ACTIVIDADES DE AULA}

Por equipos, utilizando una de las estrategias de aprendizaje cooperativo, crear un cómic en un mural sobre una actividad musical en el que aparezcan reflejadas las acciones que implican emprendimiento.

Por equipos, utilizando otra de las estrategias de aprendizaje cooperativo, crear un listado de ideas y maneras de concienciar a las personas sobre el ruido en las ciudades.

lares en el aula hace que interioricen la información sobre dicha directora.

- Brújula o puntos cardinales N-E-O-S (necesidades, emociones, objeciones o preocupaciones y sugerencias). Se propone al alumnado escribir sobre los cuatro puntos cardinales del gráfico de una brújula, como se ha indicado en cada uno de ellos, respecto al reconocimiento de los tipos de voces humanas tras la audición de una determinada obra musical.

\section{Aprendizaje cooperativo}

En párrafos anteriores hemos visto que las interacciones son uno de los tres elementos básicos a la hora de abordar el proceso de enseñanza-aprendizaje. Estas surgen del intercambio de datos, ideas y opiniones dentro de los grupos creados en el aula, a través del diálogo y los acuerdos. En la gran mayoría de ámbitos pedagógicos se valoran más estas interacciones que el propio conocimiento que se pretende obtener.

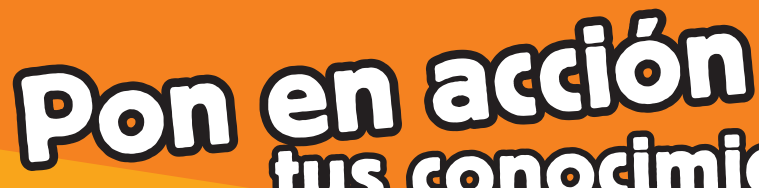 tus conodinlentos}
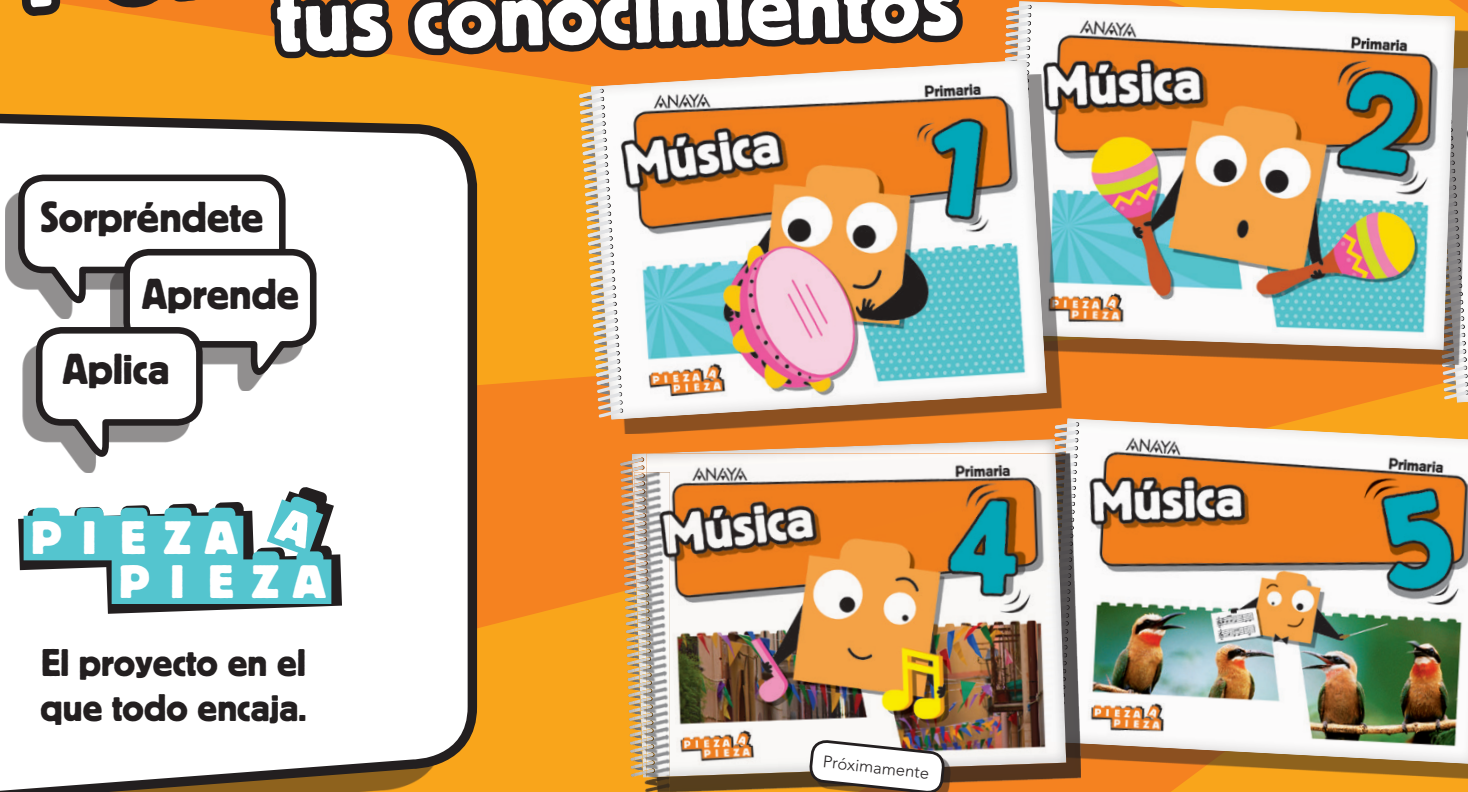

ANAYYA

El proyecto en el que todo encaja. 
A continuación, se sugieren varias actuaciones posibles para la participación de los padres en el proceso enseñanza-aprendizaje de sus hijos:

У Inventar un relato simultáneo a la escucha de "música clásica" de diferentes épocas, tanto en el hogar como en viajes realizados en coche. Primero, lo harán los adultos y, después, los hijos.

$\checkmark$ Crear una ambientación musical mientras se lee un relato o cuento, con objetos de la cocina y otros de la casa. Esto también es factible realizarlo con una noticia del periódico.

\ Realizar una dramatización mientras se canta la letra de una canción.

У Mostrar mediante un dibujo, cerámica o escultura la emoción que transmite la escucha de una música.

$\checkmark$ Proponer a los hijos que actúen como docentes y se inventen alguna actividad similar a las de su libro de música de la escuela para que la realicen los padres en casa.
7 Ser innovador, dar un paso más atreviéndose a llevar ideas a la práctica.

\# Traducir ideas en un plan de acción.

7 Trabajar en equipo.

Con las actividades musicales en el aula se puede potenciar el desarrollo de todas estas capacidades.

\section{Educación emocional}

Se sabe que aprendemos cuando hay un equilibrio entre el nivel de dificultad de una tarea y nuestra capacidad para realizarla, y que solo se aprende aquello que nos Ilama la atención y nos genera emoción.

Cuando esto ocurre, se generan emociones positivas como el humor o la felicidad. Sin embargo, si no se dan estas condiciones, surgen emociones negativas como el miedo o la ansiedad.

En el aula de música, a través de la expresión corporal, vocal e instrumental, se pueden trabajar actividades vinculadas a la superación, la autoestima, la confianza en las relaciones, y la conciencia y regulación de las emociones.

\section{Tecnologías de la información y la comunicación}

Las tecnologías de la información y la comunicación son una fuente de posibilidades para el desarrollo de las capacidades artísticas. Actualmente existen diversas aplicaciones informáticas directamente relacionadas con la generación - la transformación del sonido en formato audio o formato audiovisual. Ellas nos servirán tanto para la creación musical de canciones y obras instrumentales por parte del alumnado, como para la ambientación de imágenes, cuentos o creaciones teatrales.

Otras aplicaciones tienen como objeto grabar la propia música compuesta por el alumnado por pistas, escribir dicha música para poder leerla e interpretarla o procesar composiciones preexistentes con distintos tipos de finalidad.

También son de gran utilidad para el alumnado los vídeos digitales, para ser visualizados en el aula o en casa, a través de los cuales pueden trabajar sobre compositores e intérpretes, épocas de la 
historia de la música, técnicas instrumentales o análisis de musicogramas y partituras convencionales. Esto puede derivar, si así se plantea, en una "clase invertida" en la que los alumnos intercambian con el grupo de clase los conocimientos recibidos a través del material audiovisual.

\section{Competencias clave e interdisciplinariedad}

El desarrollo de las competencias clave, que indica la ley de educación, es sencillo en un aula de música en la que se trabaja con pedagogías activas. La adquisición de cualesquiera de ellas está interrelacionada con el desarrollo de las inteligencias múltiples detallado anteriormente:

7 Competencia en comunicación lingüística.

$\boldsymbol{\lambda}$ Competencia matemática y competencias básicas en ciencia y tecnología.

$\boldsymbol{\lambda}$ Competencia digital.

$\boldsymbol{\lambda}$ Aprender a aprender.

入 Competencias sociales y cívicas.

入 Sentido de la iniciativa y espíritu emprendedor.

$\boldsymbol{\lambda}$ Conciencia y expresiones culturales.

Por otra parte, una de las grandes ventajas de la música en el aula es su papel interdisciplinar ya que, a través de sus distintas facetas, se pueden adquirir contenidos de otras materias, como los idiomas (vocabulario, pronunciación, construcción de oraciones, gramática), las matemáticas (suma, resta, división, multiplicación, proporciones), la lengua (sílabas, diptongohiato, gramática, análisis de oraciones),

\section{HEMOS HABLADO DE}

\section{Música; pedagogía activa; inteligencias múltiples; educación emocional; aprendizaje cooperativo; rutinas de pensamiento.}

Este artículo fue solicitado por PADRES Y MAESTROS en marzo de 2018, revisado y aceptado en junio de 2018.
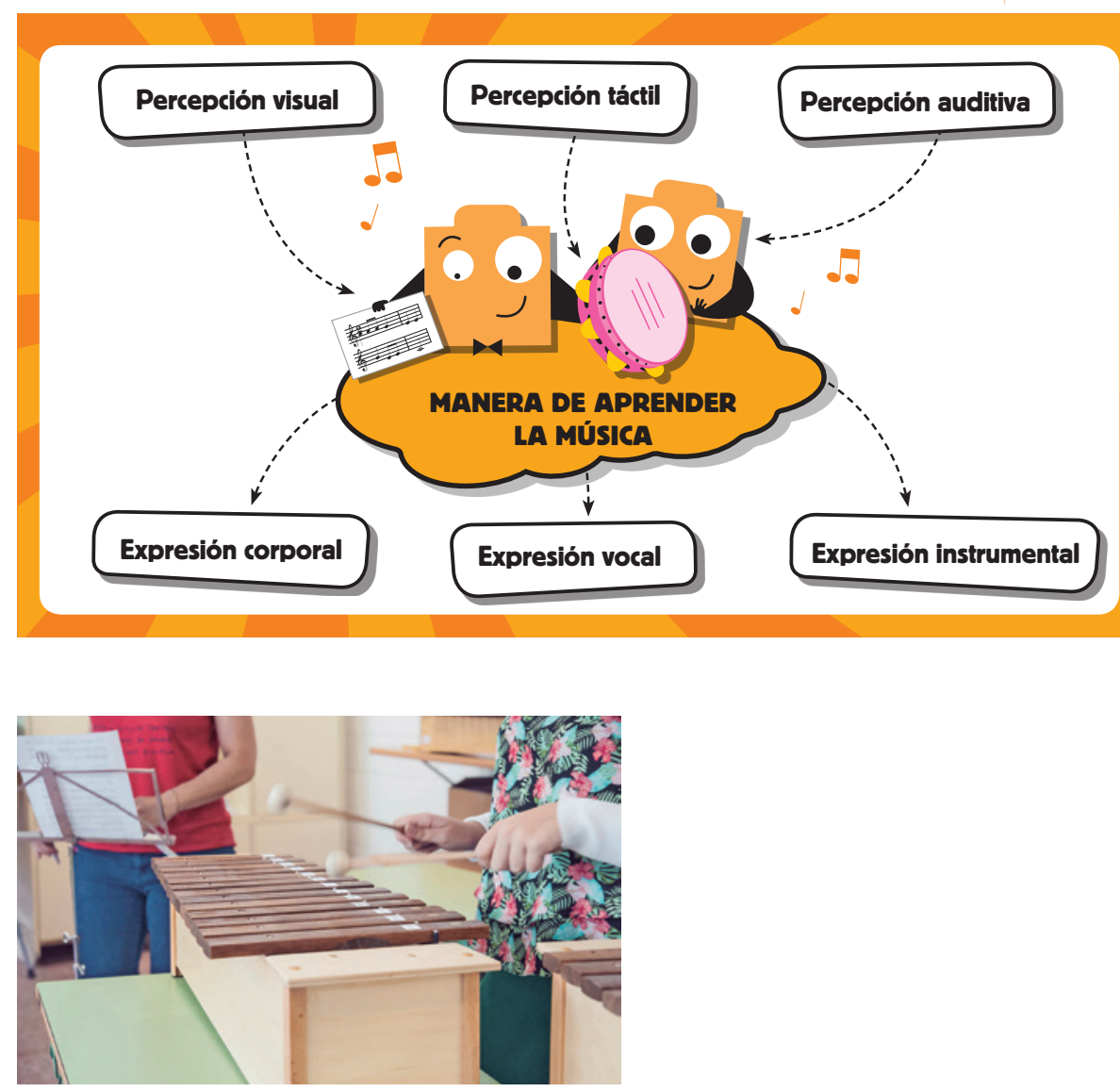

las ciencias naturales y sociales, la historia, la historia del arte, etc.

Por ejemplo, en los países en los que la música está presente en la escuela y en la sociedad, el alumnado tiene facilidad para el aprendizaje de idiomas y su pronunciación, pues ha desarrollado en mayor grado su inteligencia musical que es, junto con la lingüística, la implicada principal en dicho aprendizaje. En muchas de las comunidades autónomas de nuestro Estado esto no ocurre, y ello está directamente relacionado con el número de horas semanales de la asignatura de música en el horario planteado en el currículo y de la presencia de la música en la sociedad •

\footnotetext{
Didáctica de la Música, (71), 6-8.

Giráldez Hayes, A., y Moreno Salto, I. (2016). Pensamiento crítico y educación musical. Eufonía. Didáctica de la Música, (69), 4-6.

Murillo i Ribes, A., y Noemy Berbel Gómez, N. (2017). La experiencia musical desde el punto de vista del alumnado. Eufonía. Didáctica de la Música, (72), 4-6.
}

Arús Leita, E., y Rafael Muñoz, J. (2017). Música y emociones. Eufonía. 